\title{
Evoked potentials, reaction time and cognitive performance in on and off phases of Parkinson's disease
}

\author{
SERGIO E STARKSTEIN, ${ }^{*}+$ MARCELO ESTEGUY,* MARCELO L BERTHIER,* \\ HORACIO GARCIA,* RAMON LEIGUARDA*
}

From the Institute of Neurological Research "Dr Paul Carrea",* Buenos Aires, Argentina, and the Department of Psychiatry and Behavioral Sciences, $\dagger$ Johns Hopkins University School of Medicine, Baltimore, Md USA

SUMMARY Seven patients with Parkinson's disease and severe motor fluctuations were studied with event-related potentials, reaction and movement times and neuropsychological tests while in "off" and "on" phases. While there was a significant decrement in the P300 latency of the event-related potentials and in the duration of movement time in the "on" phase, no significant differences between on and off phases were observed in reaction time and neuropsychological tasks.

While marked changes in motor performance characterise the on and off phases of Parkinson's disease, cognitive changes have been reported to be less dramatic $^{12}$ and mainly related to verbal memory tasks that examine episodic memory (that is, Logical Memory and Paired-Associates). ${ }^{3}$ It is possible, however, that neurophysiological parameters of cognition and attention like the event-related potentials (ERPs) may demonstrate more significant differences. The P300 component of the auditory event-related potential is a measure that may reflect informationprocessing-related activities. ${ }^{4}$ While $\mathrm{P} 300$ latencies are significantly increased in Parkinson's disease patients as compared with age-matched controls, ${ }^{4}$ these measurements have not yet been correlated with the degree of cognitive fluctuations in Parkinson's disease patients with on and off phenomena.

In the present study, a group of patients with Parkinson's disease and severe motor fluctuations were studied with ERPs, reaction (RT) and movement time (MT), and a brief neuropsychological battery.

\section{Material and methods}

Seven patients (six males and one female) with idiopathic Parkinson's disease were examined after giving informed

Present address of Dr Esteguy: Department of Neurology, Columbia University School of Medicine, New York, NY, USA.

Address for reprint requests: Ramon Leiguarda, MD, Institute of Neurological Research "Dr Paul Carrea", Ayacucho 2166, 1112 Buenos Aires, Argentina.

Received 18 March 1988 and in final revised form 17 October 1988 consent. None of them was demented or had a history of alcoholism. All seven patients had normal CT findings (reported by a neuroradiologist blind to patient's diagnosis) Patients' mean age was 64.7, SD 7.2 (mean, SD) years, and the mean duration of illness was 11.6 , SD 6.7 years.

All patients were on treatment with levodopa/carbidopa (mean levodopa dosage: $718 \pm \mathbf{4 4 0} \mathrm{mg} /$ day). Three patient were also taking lisuride, two bromocriptine and one transdihydrolisuride. All patients showed severe fluctuations witho on-off phenomena as well as peak-dose dyskinesias, and two patients also showed end of dose dyskinesias.

All patients discontinued treatment with levodopa/car bidopa and dopaminergic agonists at least $24 \mathrm{hr}$ before the study. A rating scale of Parkinson's disease signs ${ }^{5}$ was scored in both the one phase (when patients' motor function was near normal) and the off phase (when patients showed severe Parkinsonian motor disabilities). ERPs were elicited by presenting patients with a random sequence of binaural tones $(60 \mathrm{~dB}, 9.9 \mathrm{~ms}$ rise fall, $50 \mathrm{~ms}$ plateau time), with the standard tone occurring $80 \%$ of the time and the target tone $20 \%$ of the time. Patients were instructed to keep a silent count of target tones, and EEG was recorded between the vertex referenced to linked mastoids with a forehead ground. The filter band pass was $\mathbf{1}-\mathbf{3 0 ~} \mathrm{Hz}$ and the EEG was digitised at $3 \mathrm{~ms} /$ point for $768 \mathrm{~ms}$, and averaged on line by a Nicolet CA-1000. RT and MT were assessed with a microcomputer as follows: patients had their dominant forefinger resting on a switch and were asked to lift and return the finger to the contact switch as fast as possible after hearing a tone. Lifting the forefinger stopped a digital clock started by the tone, and this interval was the RT. Returning the finger to the contact switch stopped a second clock started by lifting the finger, and this interval was considered to be the MT. During the testing procedure, patients rested comfortably in a semireclined position. None of them showed dyskinesias severe enough to interfere with the neurophysiological evaluation.

Following these procedures, patients were assessed on a 
Table Motor and cognitive performance in Parkinsonian patients with the on-off phenomenon

\begin{tabular}{lcc}
\hline & On & Off \\
\hline $\begin{array}{l}\text { Parkinson's disease scale scores } \\
\text { (mean)† }\end{array}$ & $11.9(7.4)$ & $38.3(8.9)$ \\
P300 latency (ms)* & $324.4(22.4)$ & $336.2(17.6)$ \\
P300 amplitude $(\mu \mathrm{V})$ & $6.37(3.54)$ & $6.78(3.52)$ \\
Reaction Time (ms) & $329.4(28.4)$ & $340.8(17.7)$ \\
Movement Time (ms) & $280.8(36.4)$ & $369.2(90.1)$ \\
WCST-categories (mean) & $1.5(2.0)$ & $2.0(1.8)$ \\
WCST-perseverations (\%) & $49.7(33.5)$ & $63.5(32.9)$ \\
BWFT-FAS words (mean) & $34.8(13.8)$ & $27.5(9.1)$ \\
Digits Forward (mean) & $5.16(0.40)$ & $5.50(0.54)$ \\
Digits Backward (mean) & $3.85(0.37)$ & $4.0(1.15)$ \\
BVRT-correct (mean) & $5.71(2.42)$ & $5.57(1.81)$ \\
\hline
\end{tabular}

${ }^{*} p$ 0.05. tp < 0.001. WCST: Wisconsin-Card Sorting Test; BWFT: Benton Word Fluency Test; BVRT: Benton Visual Retention Test. Standard deviations are shown in parentheses.

battery of neuropsychological tasks (Wisconsin Card Sorting Test (WCST), Benton's Word Fluency Test (BWFT), Digits Forward (DF) and Backward (DB) and the Benton Visual Retention test (BVRT)). After the neuropsychological evaluation was completed, patients were allowed to rest for one hour after which they received $250 \mathrm{mg}$ of levodopa/ carbidopa. The same testing procedure was repeated after patients reached their best motor scores (established before the study). Statistical analysis was done with a pairedStudent's $t$ test (two-tailed).

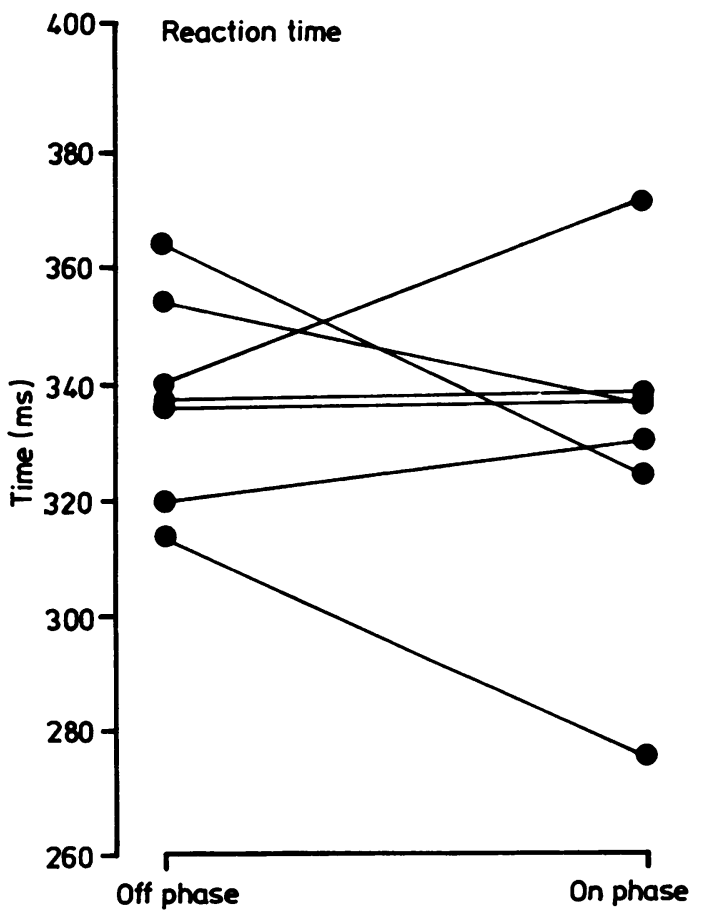

Fig 1 Reaction times values during the on and off phases.

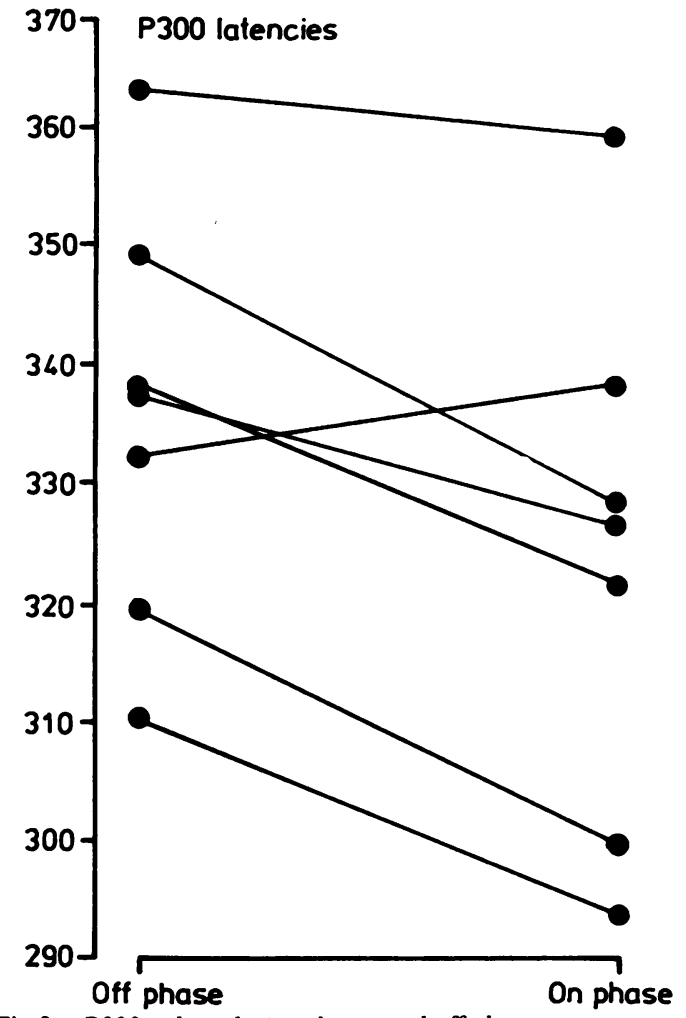

Fig 2 P300 values during the on and off phases.

\section{Results (Table)}

In the on phase, there was a significant decrease (improvement) in Parkinson's disease scores $(t=8 \cdot 10, \mathrm{df}=6, \mathrm{p}<0.001)$. There was a significant reduction in MT $(t=2.68$, df $=6, \mathrm{p}=0.036)$, but not in RT ( $t=1 \cdot 20$, df $=6, \mathrm{p}=0 \cdot 27$ ) (fig 1). P300 latency was significantly decreased during the on phase $(t=3.20, \mathrm{df}=6, \mathrm{p}=0.018)$, and this decrement was observed in six of the seven patients (fig $2)$. No significant differences were observed in $P 300$ amplitudes $(t=0.22, \mathrm{df}=6, \mathrm{p}=0.82)$. On neuropsychological testing no significant differences emerged.

\section{Discussion}

In the present study, Parkinson's disease patients showed a significant decrease in the P300 latency and MT in the on as compared to the off phase in the absence of significant changes in RT and in the performance of several neuropsychological tasks.

Hansch et $\mathrm{ll}^{4}$ reported a significant increase in the P300 latency of Parkinson's disease patients as compared with normal controls, and suggested this may 
reflect a generalised slowing in neural processing (bradyphrenia). Our present findings suggest that this slowing is state-dependent and may be present even in the absence of significant changes in the performance of several (mainly frontal lobe-related) neuropsychological tasks. While the location of P300 generators is still under debate, ${ }^{67}$ an important dopaminergic influence on P300 generation has been suggested, ${ }^{8}$ thus providing a biological rationale for the significant differences in latencies observed in on and off stages.

P300 amplitudes, on the other hand, do not seem to be affected in Parkinson's disease. Hansch et al $^{4}$ observed no significant differences in P300 amplitudes between Parkinson's disease patients and age-matched controls, and no significant differences in this parameter between on and off stages were present in the current study.

Differences in cognitive performance in on and off stages have been reported to be minor, ${ }^{3}$ and mainly related to mood fluctuations. ${ }^{12}$ Similarly, we could not find significant differences in our brief neuropsychological battery (which mainly consisted of frontal lobe-related tasks) between on and off stages. The dissociation between neuropsychological results and P300 latency results may have several explanations. Firstly, the P300 may examine different aspects of cognitive processes, which are not adequately tapped by the present neuropsychological battery. Secondly, it is possible that P300 latencies are more sensitive to cognitive changes in Parkinson's disease fluctuations and more prone to be influenced by alterations in dopaminergic brain levels. Finally, alterations in P300 latencies may not be directly associated with cognitive processes.

This study was partially supported by a grant from the
Instituto Di Tella, a grant from the University of Buenos Aires (SES), and a NARSAD Fellowship Extension Award (SES).

\section{References}

1 Brown RG, Marsden CD, Quinn N, Wyke MA. Alterations in cognitive performance and affect-arousal state during fluctuations in motor function in Parkinson's disease. J Neurol Neurosurg Psychiatry 1984;47: 454-65.

2 Girotti F, Carella F, Grassi MP, Soliveri P, Marano R, Caraceni T. Motor and cognitive performances of Parkinsonian patients in the on and off phases of the disease. J Neurol Neurosurg Psychiatry 1986;49: 657-60.

3 Mohr E, Fabbrini G, Ruggieri S, Fedio P, Chase TN. Cognitive concomitants of dopamine system stimulation in Parkinsonian patients. $J$ Neurol Neurosurg Psychiatry 1987;50:1192-6.

4 Hansch EC, Syndulko K, Cohen SN, Goldberg ZI, Potvin AR, Tourtellotte WW. Cognition in Parkinson's disease: an event-related potential perspective. Ann Neurol 1982;11:599-607.

5 Lhermitte F, Agid Y, Signoret JL. Onset and end-dose induced dyskinesias. Arch Neurol 1978;35:261-3.

6 Halgren E, Squires NK, Wilson CL, Rohrbaugh JW, Babb TL, Crandall PH. Endogenous potentials generated in the human hippocampal formation and amygdala by infrequent events. Science 1980;210: 803-5.

7 Wood CC, Allison T, Goff WR, Williamson PD, Spencer DB. On the origin of $\mathrm{P} 300$ in man. Prog Brain Res 1980;54:51-56.

8 Thompson JW, Ashton H, Golding JF, Marsh VR Pharmacology of event-related potentials in humans. In: McCallum WC, Zappoli R, Denoth F, eds. Cerebral Psychophysiology: Studies In Event-Related Potentials. Amsterdam: Elsevier Publishers B.V., North-Holland, 1986:374-80. 